\title{
Cogitation on Routine Drowned Cases in Mazandaran Province: a Case Study in between the Year 2008 to 2013
}

\section{Farzad Bozorgi', Hojjat Derakhshanfar ${ }^{2}$, Seyed Mohammad Hoseininejad ${ }^{1 *}$, Ali Abbasi ${ }^{3}$,AbolghasemLali', Mehrnoush Tavakoli}

${ }^{1}$ Emergeny Medicine department, Mazandaran University of medical sciences, Sari, Iran.

${ }^{2}$ Emergeny Medicine department, ShahidBeheshti University of medical sciences, Tehran, Iran

${ }^{3}$ Forensics medicine,Mazandaran University of medical sciences, Sari, Iran.

Study Area: Mazandaran Province, Iran

Coordinates: $36.2262^{\circ} \mathrm{N}, 52.5319^{\circ} \mathrm{E}$

Key words: Caspian Sea, Death Cause

\section{Introduction:}

Death cause could be reduced by taking proper action which eventually occurs due to falling into the water source and eventually drowning.This factor has been highly overlooked during the study of public health problems while preparing various relevant strategies (Brundtland, 2002; van Beeck et al., 2005). According to the latest def inition offered by the World Health Organization (WHO), drowning death is the respiratory failure resulted from being submerged/immersed in liquid (Burford et al., 2005; Kallas, 2008). According to some estimation of the WHO and other relevant organization, a number of deaths caused by drowning in the world are $\sim 400,000$ individuals per year (Brundtland, 2002; ILF, 2007).

These statistics indicate that drowning could be considered as the third reason of death which stands after the deaths caused by unintentional injuries in traff ic and fall accidents in the world. Surprisingly, $97 \%$ of all of these deaths occur in the nations of low or average incomegrowth (Peden \& McGee, 2003). As per the death registration record of Tehran 2002, in Iran itself, every year on an average 1200 deaths occurs because of drowning. Thus as per the situation it should be considered as a serious problem worldwide. Besides it the other main cause of death refers to injuries in the entire

\section{Abstract}

Since last few decades drowned cases are increasing in Mazandaran Province which could be directly estimated while going through the data available at the pre-hospital emergency department of the aforesaid Province and legal medicine organization. Mazandaran Province receives a great number of tourists every year, especially in summer and for them swimming in the Caspian Sea is the major motive of attraction. Our study was conducted on the descriptive-periodical basis in Mazandaran Province from June to September within 2008- 2013 by using the available resources at above mentioned units of the Mazandaran Province.With reference to the place of the drowning,death causes for most of the individuals indicate poor quality or ineff iciency of rescue systems. Possible suggestions have been given to overcome such accidents.

nation due to the road accidents, burns and falls.

Areawise the Caspian Sea is the largest enclosed inland water body on the Earth. Among the numerous advantages offered to the neighbouring countries, one of the main attraction is its elegant and natural tourist sights spreciall on its Souther beaches. Various factors such as favorable weather in summer, long sunny days, seawater temperature, relative humidity, forest coverage, elegant natural sights, easy access to Tehran and other relevant urban areas of Iran including recreational equipment, Mazandaran Province is already considered as one of the most favorable regions in Iran for development of tourism industry especially during summer season.Thus, it annually attracts over $25,000,000$ domestic tourists who are interested in recreational tourism. In the northern parts of Iran, drowning cases have already been regarded as the second cause of unintentional injuries (Naghavi, 2007). According to the recent detailed report, deaths caused by drowning in the provinces of Mazandaran, Iran was 8.6 per each 100,000 inhabitants. This statistics indicate red alert to the problem of drowning in Mazandaran Province. It seems that a comprehensive and perfect prevention program is urgently required to confront with such accidents related to public safety in the Province. Since the $f$ irst step for control of and intervention with any type of problems addressing public

*Corresponding Author: drhoseininejad@yahoo.com 
safety is to identify its routine parameters and to shed some light on existing lack of relevant information in Iran (Sheikhazadi \& Ghadyani, 2009; Soori \& Naghavi, 1999; Akbari et al., oo6) In this study we tried to collect the corresponding information available at pre-hospital emergency department and legal medical organization of this Province and tried to correlate with various factors influence such drowning.

\section{Materials and methods:}

On a basis of the descriptive-periodical this study was conducted in Mazandaran Province between June to September during 2008- 2014. Required data were collected from pre-hospital emergency department of Mazandaran Province and legal medicine organization of Mazandaran Province by using required census.

During this study, we have included the available information of those who contacted the pre-hospital emergency department due to drowning or those relevant cases to which a burial permit was issued and registered in between the year 2008 to 2014. The methodology of our study was based on a preplanned questionnaire comprising gender differentiation, the place of drowning, drowning inside or outside the safe-sea project or inside a river or swimming pool, dispatch, outpatient treatment, death before receiving ambulance services or cancellation of the mission. SafeSea addresses the strategic objective to reduce the risk of injury in complex systems through advanced personal protective equipment.

In order to describe the research $\mathrm{f}$ indings, the descriptive statistic has been used. Corresponding data collected by SPSS 19 software was analyzed (CHICAGO, IL,USA). In order to compare the qualitative variables, $\mathrm{K}_{2}$ or Fischer tests and for comparison of average, at-test were used respectively.

Results:

This study has been conducted by using a census in all the drowned cases within four months i.e., from June to September 21 in 2008-2014.

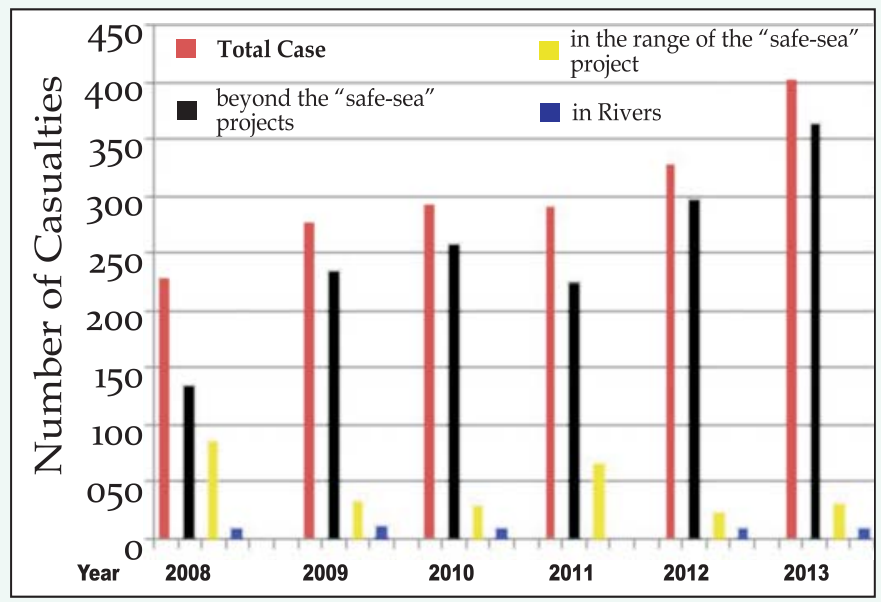

Figure 1: Total number of drowning during the studied period
Tables: Yearwise type and management of the drowned cases

\begin{tabular}{|c|c|c|c|c|c|c|}
\hline Year & 2013 & 2012 & 2011 & 2010 & 2009 & 2008 \\
\hline Refer & 173 & $\begin{array}{l}132 \\
(40 / 12 \%)\end{array}$ & $\begin{array}{l}147 \\
\%)(50 / 34 \%)\end{array}$ & $\begin{array}{l}113 \\
\text { 0) }(38 / 43 \%)\end{array}$ & $\begin{array}{l}88 \\
(31 / 76 \%)\end{array}$ & $\begin{array}{l}82 \\
(35 / 96 \%)\end{array}$ \\
\hline $\begin{array}{l}\text { Out } \\
\text { patient }\end{array}$ & 96 & $\begin{array}{l}74 \\
(22 / 49 \%\end{array}$ & $\begin{array}{c}61 \\
\%)(20 / 89\end{array}$ & 79 & $\begin{array}{l}62 \\
\text { 6) }(22 / 38 \%\end{array}$ & $\begin{array}{l}43 \\
(8 / 85 \%)\end{array}$ \\
\hline Death & 93 & $\begin{array}{l}91 \\
(27 / 65 \% \\
\end{array}$ & $\begin{array}{l}50 \\
\%)(17 / 12 \%)\end{array}$ & $\begin{array}{l}56 \\
(19 / 04 \%) \\
\end{array}$ & $\begin{array}{l}98 \\
(35 / 37 \%)\end{array}$ & $\begin{array}{l}58 \\
(25 / 43 \%) \\
\end{array}$ \\
\hline $\begin{array}{l}\text { Mission } \\
\text { Cancelled }\end{array}$ & 44 & $\begin{array}{l}33 \\
(9 / 72 \%)\end{array}$ & $\begin{array}{l}34 \\
(11 / 64 \%)\end{array}$ & $\begin{array}{l}46 \\
(15 / 64 \%)\end{array}$ & $\begin{array}{l}29 \\
(10 / 46 \%)\end{array}$ & $\begin{array}{l}45 \\
(19 / 73 \%)\end{array}$ \\
\hline $\begin{array}{l}\text { CPR } \\
\text { Adequate }\end{array}$ & $\begin{array}{l}11 \\
(2 / 73 \\
\end{array}$ & $\begin{array}{l}08 \\
2 / 43 \%)\end{array}$ & $\begin{array}{l}15 \\
(5 / 13 \%)\end{array}$ & $\begin{array}{l}12 \\
(4 / 08) \\
\end{array}$ & $\begin{array}{l}10 \\
(3 / 61 \%)\end{array}$ & $\begin{array}{l}05 \\
(2 / 19 \%) \\
\end{array}$ \\
\hline CPR & $\begin{array}{l}40 \\
(7 / 46\end{array}$ & $\begin{array}{l}22 \\
(6 / 68 \%)\end{array}$ & $\begin{array}{l}15 \\
(5 / 13 \%)\end{array}$ & $\begin{array}{l}27 \\
(9 / 18 \%)\end{array}$ & $\begin{array}{l}36 \\
(12 / 63 \%)\end{array}$ & $\begin{array}{l}10 \\
(8 / 77 \%)\end{array}$ \\
\hline
\end{tabular}

Table 1: Yearwise Gender ration in

\begin{tabular}{|lllllll|}
\hline Year & $\mathbf{2 0 1 3}$ & $\mathbf{2 0 1 2}$ & $\mathbf{2 0 1 1}$ & $\mathbf{2 0 1 0}$ & $\mathbf{2 0 0 9}$ & $\mathbf{2 0 0 8}$ \\
\hline Male & 317 & 248 & 216 & 207 & 204 & 160 \\
& $(78 / 85 \%)$ & $(75 / 37 \%)$ & $(73 / 46 \%)$ & $(70 / 4 \%)$ & $(73 / 64 \%)$ & $(70 / 17 \%)$ \\
\hline Female & 115 & 81 & 76 & 85 & 73 & 68 \\
& $(28 / 60 \%)$ & $(24 / 62 \%)$ & $(25 / 85 \%)$ & $(28 / 91 \%)$ & $(26 / 35 \%)$ & $(29 / 82 \%)$ \\
\hline
\end{tabular}

\section{Discussion:}

SEarlier the drowning statistics were already presented by Sheikhazadi \& Ghadyani (2009) against the Mazandaran, Guilan and Golestan provinces possessing long beaches, and other provinces namely Esfahan, Khuzestan, Kermanshah and Lorestan where flowing river tributaries with high water levels and other natural features attracts the tourists. Many researchers have already published reports on the effect of geophysical factors and geographical structures which affect the drowning (Sheikhazadi \& Ghadyani, 2009; Hedberg et al., 1990; Davis \& Smith, 1985; Pearn, 1985; Shetty \& Shetty, 2007; Wong \& McNamara, 1984).

All such studies indicated that most drowning cases have occurred during peakd tourist season. Indeed to escape from the excessively high temperature in summer and spring people are drown towards deeper zones of water causing such accidents. Thus, we have concentrated on the case of drowning only during the hot seasons in Mazandaran Province (From June to September) during 2008- 2014. Our data indicated that most of the drowned were males $(73.64 \%)$, which supports the earlier studies conducted elsewhere (Peden \& McGee, 2003; Tan, 2004; Byard et al., 2001; O'Shea, 1991; Tan et al., 1997).

One of the major cause for deaths in to Caspian Sea is the flowing sand on the seabed that often disturbs the balance of the tourist (Meshkat, 2008). Further, the rise in the sea level, destruction due to anthropogenic pressure, the sinking of the forest regions and rice-processing workshops altogether have already unleveled many beaches of the Caspian Sea. 
Swimming for the beginners (learning case) is also one of the major cause that increase the number of drowning. Since learning swimming is also a part of religious teachings in Muslims i.e., encouraging people of the society and their families to learn swimming and to develop more facilities for this purpose is of great importance. Presently in many advanced nations all over the world; swimming is taken as a subject and taught to the students as one of their courses. It should be noted that knowledge of swimming technique should not cause overconf idence by swimmers, a casual approach towards it may cause accidents. From among other cases that should be taken into consideration is to make people aware of dangers in swimming beyond the protected zones. Moreover, as about 3/4th of the drowning occurs in summer, over crowding in the protected areas should be reduced through the restriction of the protected zones in this season and also it causes that increase in number of people is attracted to swimming within the said zones (Figure-1). Furthermore, a few personnels under the name of the shore patrol must be deployed in the places with high risk of drowning and to prohibit people from swimming in unprotected zones. Most of the death at the place where drowning occurs reveal def iciency or shortage of rescue teams for the treatment of the drowned.

Acknowledgements:

The authors are grateful to thanks emergency medicine departments nurses for secretarial assistance.

\section{References:}

Akbari, M.E., Naghavi, M. \& Soori, H. (2006): Epidemiology of deaths from injuries in the Islamic Republic of Iran. East Mediterr Health J., 12(3,4):382-390.

Brundtland, G.H. (2002): Reducing risks to health, promoting healthy life. $J A M A, 288(16): 1974$.

Burford, A.E., Ryan, L.M. \& Stone, B.J., Hirshon, J.M. \& Klein, B.L.. (2005): Drowning and near-drowning in children and adolescents. Pediatr. Emerg. Care, 21:610-919.

Byard, R.W., Houldsworth, G., James, R.A. \& Gilbert, J.D.(2001): Characteristic features of suicidal drownings: a 20 -year study. Am. JForensic Med. Pathol., 22(2):134-138.

Davis, S. \& Smith, L.S. (1985): The epidemiology of drowning in Cape Town 1980-1983. S. Afr. Med. J., 68: 739-742.
Hedberg, K., Gunderson, P., Vagas, C., Osterholm, M. \& Mac Donald, K. (1990): Drowning in Minnesota 1980- 85: a population based study. Am. J. Publ. Health, 80: 1071-1074

ILF- International Lifesaving Federation (2007): World Drowning Report, edition: Brussels.

Kallas, H.J., Behrman, R.E., Kliegman, R.M. \& Jenson, H.B. (2008): Drowning and submersion injury. Nelson Text book of Pediatrics. 18th ed. Philadelphia: Saunder's. p. 438-449.

Meshkat, R.A.(2008): Heat and risk of drowning.Ghods newspaper.; $5850-5813$.

Naghavi, M. (2007): Prof ile of Death in 29 Provinces of Iran in Year 2004. Tehran: Ministry of Health and Medical Education.

O'Shea, J.S.(1991): House-f ire and drowning deaths among children and young adults. Am. J. Forensic Med. Pathol., 12(1): 33-35.

Pearn, J. (1985): Path physiology of drowning. Med J Aust., 142: 586-88.

Peden, M.M. \& McGee, K. (2003): The epidemiology of drowning worldwide. Inj. Control Saf. Promot., 10(4):195-199

Sheikhazadi, A. \& Ghadyani, M.H. (2009): Epidemiology of Drowning in Isfahan Province, center of Iran. $L R M S, 14(2): 79-$ 87.

Sheikhazadi, A. \& Ghadyani, M.H. (2010): Epidemiology of drowning in Mazandaran province, north of Iran. Am. J. Forensic Med. Pathol., 31(3):236-42

Soori, H. \& Naghavi, M. (1999): Deaths from unintentional injuries in rural areas of the Islamic Republic of Iran. East Mediterr. Health J., 5(1):55-6o.

Shetty, S.K. \& Shetty, M. (2007): Epidemiology of drowning in Mangalore, a coastal Taluk of South India. J. Forensic Legal Med., 14: 410-415.

Tan, R.M. (2004): The epidemiology and prevention of drowning in Singapore. Singapore Med. J., 45(7):324-329.

Tan, Z., Li, X. \& Bu, Q. (1998): Epidemiological study on drowning in Wujin, Jiangsu, 1997. Zhonghua Liu Xing Bing XueZaZhi.; 19(4):208-210.

Van Beeck, E.F., Branche, C.M., Szpilman, D., Modell, J.H. \& Bierens, J.J.L.M. (2005): A new def inition of drowning: towards documentation and prevention of a global public health problem. Bull. World Health Organ., 83: 853-856.

Wong, L.L. \& McNamara, J.J. (1984): Salt water drowning. Hawaii Med.J., 43:208-210.. 